\title{
PENGARUH EXPERIENTIAL MARKETING TERHADAP LOYALITAS PELANGGAN MELALUI KEPUASAN PELANGGAN SEBAGAI VARIABEL INTERVENING DI SENGKALING KULINER "SEKUL" MALANG
}

\author{
Wahyu Amrullah \\ Department of Management FEB UMM \\ E-mail :wahyuamrullah123@gmail.com
}

\begin{abstract}
The research is to analyze experiential marketing consisting of sense, feel, think, act, and relate, customer satisfaction, customer loyalty and to analyze impact of experiential marketing on customer loyalty through customer satisfaction as an intervening variable at Sengkaling Kuliner "SeKul" Malang. Use data from quetionnaires of the sample 100 respondents with purposive sampling technic. This research is descriptive quantitative study with survey method. Test instrument used include the validity and reliability test. Analysis data method used is a range of scale, path analysis, and hypothesis testing. The result of the calculation of experiential marketing consisting of sense, feel, think, act, and relate scale range is genelrally categorized as good. Customer satisfaction and customer loyalty based on the result of the calculation of the scale range is generally categorized as high. These result indicate that the effect of indirectly greater than the direct effect of this proves that customer satisfaction to intercede or mediate the effect of experiential marketing to customer loyalty. This indicates that the experiential marketing significant effect on the customer loyalty through customer satisfaction.
\end{abstract}

Keywords: experiential marketing, customer satisfaction, customer loyalty

\section{PENDAHULUAN}

Di era global sekarang ini segala bidang usaha khususnya bisnis kuliner terus berkembang pesat dan dinamis dari konsep konvensional menjadi konsep modern dan terus bersaing untuk memenuhi segala kebutuhan dan keinginan pelanggan. Untuk menghadapi persaingan tersebut, perusahaan dituntut harus mempunyai keunggulan bersaing untuk dapat bertahan. Selain itu salah satu strategi yang tepat untuk terus bertahan di persaingan yang ketat dalam dunia usaha sekarang ini adalah dengan mempertahankan loyalitas pelanggannya.

Tanpa adanya loyalitas dari pelanggan, perusahaan tidak akan berkembang dengan baik, bahkan dapat mengalami penurunan usaha yang bisa mengancam eksistensi perusahaan. Membangun loyalitas pelanggan bukanlah sesuatu perkara yang mudah untuk dilakukan oleh perusahaan. Untuk mendapatkan 
loyalitas pelanggan, perusahaan perlu menerapkan strategi pemasaran yang tepat agar dapat bersaing.

Salah satu strategi yang harus dilakukan untuk mendapatkan keunggulan bersaing adalah dengan cara focus terhadap konsumen. Focus terhadap konsumen dapat dilakukan dengan memonitor pengalaman atau experience yang dirasakan dari kontak tersebut (Gentille, Spiller dan Noci, 2007:5). Dalam pendekatan ini, pemasar menciptakan produk atau jasa dengan menyentuh panca indera konsumen, menyentuh hati dan merangsang pikiran konsumen. Jika produk dapat menyentuh nilai emosional pelanggan secara positif maka dapat menjadi memorable experience antara perusahaan dengan pelanggan.

Berdasarkan hasil penelitian mengenai perilaku pembelian makan diluar rumah menggunakan metode penelitian online terhadap responden di sejumlah Negara termasuk Indonesia dengan hasil sekitar $44 \%$ masyarakat Indonesia mencari makan diluar rumah satu sampai tiga kali dalam seminggu dan sekitar 38 $\%$ melakukannya sebulan sekali, dan $60 \%$ dilakukan pada saat malam hari. Dengan melihat fenomena yang terjadi pada masyarakat saat ini, peluang untuk melakukan usaha di bidang kuliner sangatlah besar. Selain kebutuhan makan dan minum yang tidak akan pernah meredup, bisnis kuliner juga menjadi salah satu sarana rekreasi bagi beberapa golongan masyarakat.

Salah satu jenis industri boga yang ada di kota Malang adalah "Sengkaling Kuliner (SeKul)". Sengkaling Kuliner (SeKul) merupakan ikon wisata kuliner baru di kota Malang, yang dibangun di kawasan Taman Rekreasi Sengkaling (TRS). Konsep penggabungan Wisata Kuliner dengan Taman Rekreasi, didukung pengaturan Site Plan, Desain Gedung, Penataan Outlet dan Lighting System yang mumpuni sehingga memberi kesan sensasional yang tak akan terlupakan.

Sengkaling Kuliner (SeKul) tidak lepas dari persaingan bisnis yang semakin ketat dalam jenis usaha kuliner. Hal ini tampak dengan berdirinya berbagai bisnis kuliner yang ada di kota Malang. Pihak pengelola usaha harus benar-benar memikirkan strategi yang tepat agar perusahaannya tetap bertahan meskipun banyak ancaman dari kompetitor dengan bidang usaha sejenis. Semakin banyak jenis usaha kuliner membuat pelanggan memiliki berbagai macam pilihan sesuai dengan keinginan mereka.

Kepuasan yang diperoleh pelanggan saat berkunjung dapat dihasilkan dari experience, sehingga pelanggan sering kali akan menceritakan pengalamannya selama berkunjung kepada keluarga, teman-teman dan orang-orang sekitar, serta akan membuat kunjungan kembali sehingga akan menjadi pelanggan yang loyal.Dalam beberapa bulan terakhir banyak orang yang datang dan melakukan pembelian di Sengkaling Kuliner terutama pada saat weekend (akhir pekan) dan terlihat dari meningkatnya pelanggan yang datang dalam tiga bulan terkhir ke Sengkaling Kuliner. Hal tersebut bisa dilihat dari data penjualan Sengkaling Kuliner bulan Agustus, September, dan Oktober tahun 2016. 
Pada bulan Agustus terdapat 3.583 orang yang datang ke Sengkaling Kuliner, bulan September sebanyak 4.574 orang dan bulan Oktober sebanyak 6.160 orang. Untuk data yang lebih rinci dan jelas mengenai jumlah pelanggan yang datang dan melakukan pembelian (dalam mingguan) di Sengkaling Kuliner dari bulan Agustus-Oktober 2016 dapat dilihat di tabel di bawah ini sebagai berikut

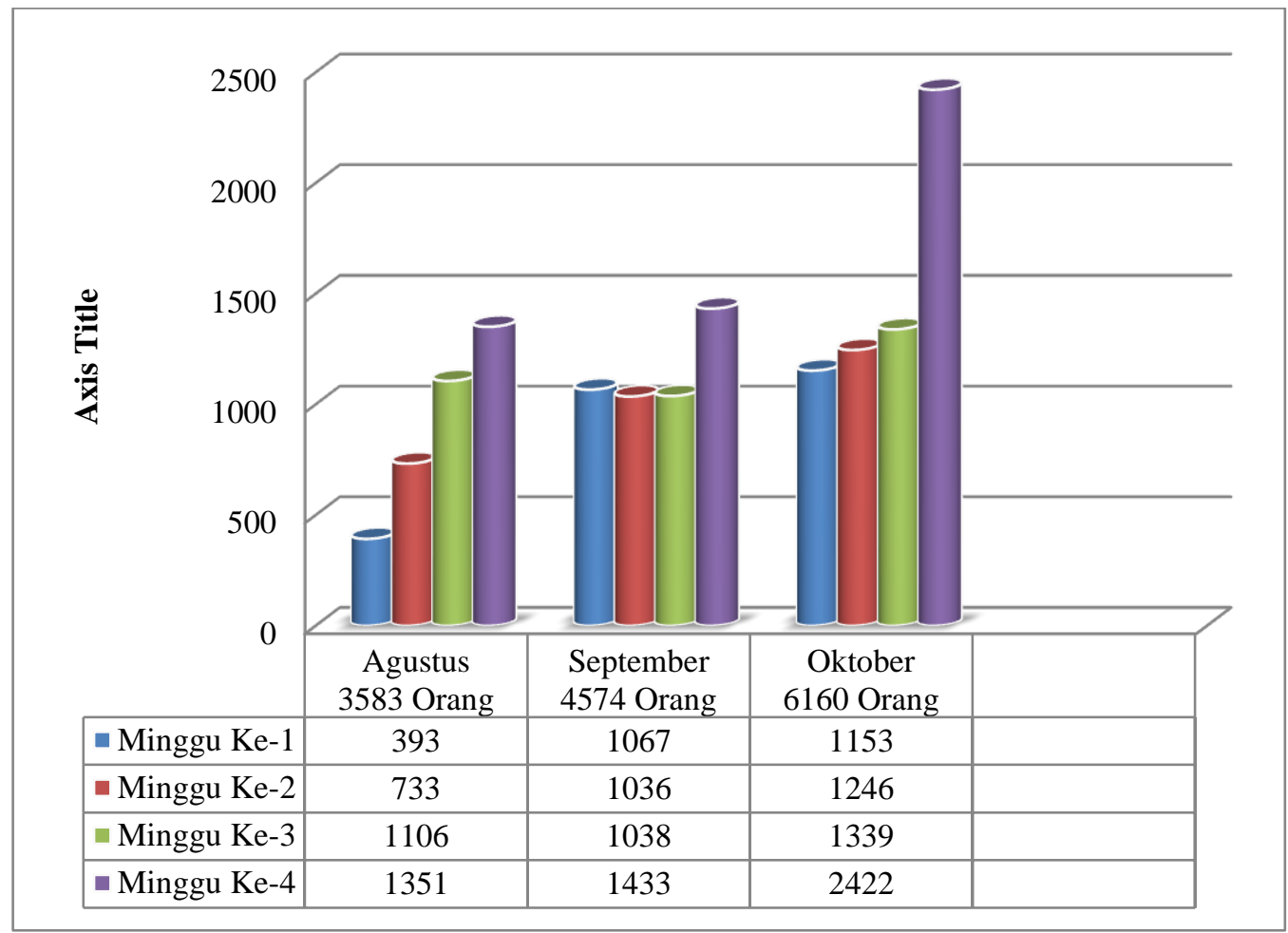

Gambar 1. Grafik Jumlah Pelanggan

Berdasarkan data di atas terlihat jelas bahwa pelanggan Sengkaling Kuliner mengalami peningkatan dalam waktu tiga bulan terakhir. Akan tetapi berdasarkan informasi yang penulis dapatkan ketika wawancara dengan Manajer Pemasaran Sengkaling Kuliner dari awal berdirinya Sengkaling Kuliner yang dulu namanya Sengkaling Food Festival sampai awal tahun 2016 terjadi perlambatan peningkatan volume penjualan dikarenakan beberapa faktor salah satunya adalah penerapan strategi pemasaran yang kurang menarik dan memikat.
Hal tersebut merupakan sebuah dilema bagi perusahaan yaitu mereka dihadapkan dengan ketidakmampuan mereka memenuhi keinginan konsumen. Namun hal yang menarik disini adalah dimana Sengkaling Kuliner "SeKul" dalam beberapa bulan terakhir ini di tahun 2016 terlihat dari gambar di atas mengalami peningkatan volume penjualan. Dalam hal ini Sengkaling Kuliner "SeKul" menghadapi tantangan yaitu dituntut untuk tetap bertahan dan meningkatkan jumlah pendapatan serta terciptanya kepuasan pelanggan yang akan 
bergerak ke terciptanya loyalitas pelanggan.

Berdasarkan dari fenomena yang terjadi di atas maka penulis tertarik untuk melakukan penelitian yang berkaitan dengan pengaruh experiential marketing terhadap kepuasan pelanggan dan loyalitas pelanggan serta pengaruh langsung dan tidak langsung terhadap loyalitas pelanggan. Dalam melakukan penelitian ini, ada beberapa tujuan yang penulis harapkan dapat dicapai yakni : (1) untuk mendeskripsikan experiential marketing, kepuasan pelanggan, dan loyalitas pelanggan Sengkaling Kuliner "SeKul” Malang. (2) untuk mengetahui pengaruh experiential marketing terhadap kepuasan pelanggan di Sengkaling Kuliner "SeKul" Malang. (3) untuk mengetahui pengaruh kepuasan pelanggan terhadap loyalitas pelanggan di Sengkaling Kuliner "SeKul" Malang. (4) untuk mengetahui pengaruh experiential marketing terhadap loyalitas pelanggan di Sengkaling Kuliner "SeKul" Malang. (5) untuk mengetahui pengaruh experiential marketing terhadap loyalitas pelanggan melalui kepuasan pelanggan di Sengkaling Kuliner "SeKul" Malang.

\section{TINJAUAN PUSTAKA}

Experiential marketing adalah pendekatan pemasaran yang melibatkan emosi dan perasaan konsumen dengan menciptakan pengalaman-pengalaman positif sehingga konsumen melakukan keputusan pembelian dan fanatik terhadap suatu produk (Schmitt, 2001).
Schmitt (2007:47) experiential marketing adalah suatu cara untuk membuat pelanggan mendapatkan pengalaman melalui panca indera (sense), menciptakan pengalaman afektif (feel), menciptakan pengalaman berpikir secara kreatif (think), menciptakan pengalaman pelanggan yang berhubungan dengan tubuh secara fisik, dengan perilaku dan gaya hidup serta dengan pengalaman-pengalaman sebagai hasil dari interaksi dengan orang lain (act), juga menciptakan pengalaman yang terhubung dengan keadaan sosial, gaya hidup, dan budaya yang dapat direfleksikan merek tersebut yang merupakan pengembangan dari sensations, feelings, cognitions dan actions (relate).

Kepuasan pelanggan adalah suatu perasaan senang atau kecewa yang timbul dengan membandingkan kinerja yang diharapkan produk (atau hasil) terhadap ekspektasi konsumen. Jika kinerja gagal memenuhi ekspektasi, pelanggan akan merasa tidak puas. Jika kinerja sesuai dengan ekspektasi, pelangganakan merasa puas. Jika kinerja melebihi ekspektasi, pelanggan akan merasa sangat puas (Kotler, 2009:p139). Indikator kepuasan pelanggan dalam penelitian ini terdiri dari kesesuaian harapan, kemudahan dalam memperoleh, dan menciptakan citra merek.

Kotler dan Keller (2012:4) "A commitment to rebuy or repatronizea a preferred product or service" Loyalitas adalah komitmen untuk membeli kembali atau pembelian secara berulang-ulang produk atau jasa yang lebih disukai. Berdasarkan 
pemaparan teori diatas dapat disimpulkan bahwa loyalitas pelanggan adalah kedalaman perasaan melebihi kepuasan dan ditunjukkan pada perilaku pelanggan setelah mengkonsumsi produk atau jasa yang berakibat kemungkinan pembelian kembali.

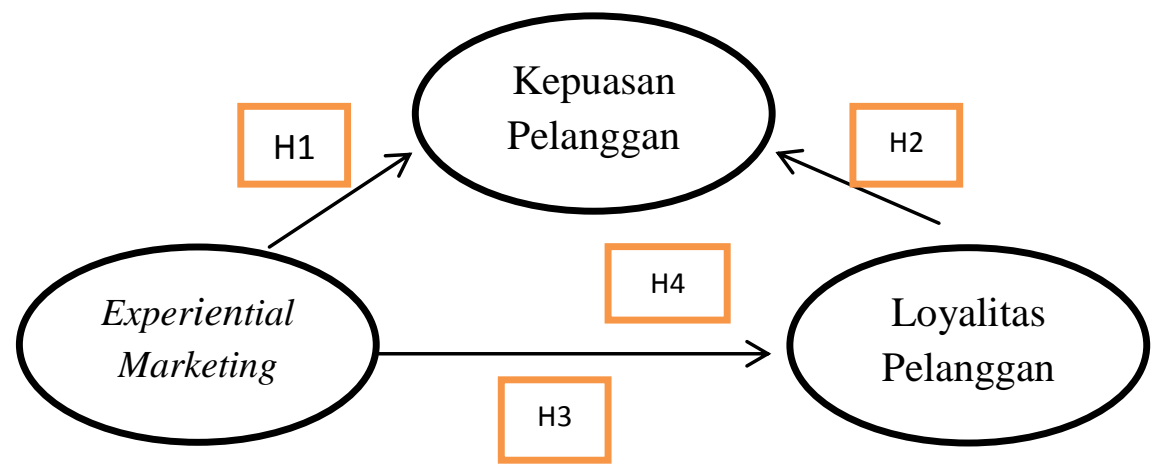

Gambar 2. Kerangka Pikir Penelitian

Hipotesis yang diajukan dalam penelitian ini yaitu, H1, Experiential Marketing berpengaruh signifikan terhadap kepuasan pelanggan. $\mathrm{H} 2$, Kepuasan pelanggan berpengaruh signifikan terhadap loyalitas pelanggan. $\mathrm{H} 3, \quad$ Experiential marketing berpengaruh signifikan terhadap loyalitas pelanggan. H4, Experiential marketing berpengaruh signifikan terhadap loyalitas pelanggan melalui kepuasan pelanggan.

\section{METODE PENELITIAN}

Penelitian ini dilakukan di Sengkaling Kuliner "SeKul" Malang yang beralamatkan di Jl. Raya Mulyoagung No. 188, kecamatan Dau, kabupaten Malang. Jenis penelitian yang digunakan adalah penelitiandeskriptif sedangkan metode yang digunakan adalah metode survei. Populasi dalam penelitian ini adalah seluruh pelanggan Sengkaling Kuliner.

Teknik sampling yang digunakan dalam penelitian ini adalah purposive sampling yaitu cara pengambilan sampel yang didasarkan pada pertimbangan-pertimbangan tertentu dimana pertimbangan atau kriteria yang dijadikan sampel dalam penelitian ini adalah pelanggan yang lebih dari satu kali melakukan kunjungan atau pembelian produk Sengkaling Kuliner "SeKul” Malang.

Dalam penelitian ini terdapat tiga variabel. Experiential marketing sebagai variabel independent, kepuasan pelanggan dan loyalitas pelanggan sebagai variabel dependent, dan kepuasan pelanggan sebagai variabel mediasi. Jenis data yang digunakan dalam penelitian ini adalah atau kuantitatif yaitu data yang diperoleh dalam bentuk angka yang dapat dihitung. primer yaitu data yang didapat dari sumber pertama atau secara langsung dari perusahaan untuk dijadikan bahan penelitian. Teknik pengumpulan data pada penelitian ini menggunakan kuesioner dengan cara memberi seperangkat pertanyaan dan pernyataan tertulis kepada responden untuk dijawab. Dalam penelitian ini tanggapan atau jawaban dari responden diukur menggunakan skala likert. 
Uji instrumen yang digunakan dalam penelitian ini menggunakan uji validitas, suatu instrument dikatakan valid jika mempunyai validitas tinggi dan mampu mengukur variabel yang diteliti secara tepat. Suatu instrument dikatakan valid jika mempunyai $r$ hitung lebih besar daripada $\mathrm{r}$ tabel. Uji reliabilitas, uji ini diperlukan untuk mengetahui kestabilan alat ukur. Suatu instrumen penelitian dikatakan reliabel. Apabila nilai alpha $>$ atau $=0,06$.
Beberapa teknik analisis data dalam penelitian ini adalah Rentang Skala, yaitu alat yang digunakan untuk mengukur danmenilai variabel yang diteliti dengan menggunakan rumus sebagai berikut:

$$
R S=\frac{n(m-1)}{m}
$$

Berdasarkan perhitungan rentang skala diperoleh sebesar 80, dengan demikian skala penelitian setiap kriteria dari variabel Experiential marketing, kepuasan pelanggan, dan loyalitas pelanggan sebagai berikut:

Tabel 1. Rentang Skala Variabel Penelitian

\begin{tabular}{cccc}
\hline $\begin{array}{c}\text { Rentang } \\
\text { Skala }\end{array}$ & $\begin{array}{c}\text { Experiental } \\
\text { Marketing }\end{array}$ & $\begin{array}{c}\text { Kepuasan } \\
\text { Pelanggan }\end{array}$ & Loyalitas Pelanggan \\
\hline $100-179$ & Sangat Tidak Baik & Sangat Tidak Puas & Sangat Tidak Loyal \\
$180-259$ & Tidak Baik & Tidak Puas & Tidak Loyal \\
$260-339$ & Cukup Baik & Cukup Puas & Cukup Loyal \\
$340-419$ & Baik & Puas & Loyal \\
$420-500$ & Sangat Baik & Sangat Puas & Sangat Loyal \\
\hline
\end{tabular}

Analisis yang digunakan dalam penelitian ini adalah Analisis Linear Berganda dengan Mediasi yang tujuannya untuk mengetahui seberapa besar pengaruh lebih dari satu variabel bebas terhadap satu variabel terikat (Ghozali, 2009).

Uji yang digunakan dalam penelitian ini adalah uji Mediasi atau uji sobel test. Uji variabel mediasi dengan metode ini dilakukan dengan menguji kekuatan pengaruh tidak langsung variabel bebas (X) terhadap variabel tergantung (Y) melalui variabel mediasi $(\mathrm{Z})$ atau menguji signifikasi pengaruh tak langsung (perkalian pengaruh langsung variabel bebas terhadap variabel mediator (a) dan pengaruh langsung variabel mediator terhadap variabel dependen menjadi (ab) dengan standard error yang akan menghasilkan nilai t statistik.

\section{HASIL DAN PEMBAHASAN}

Uji validitas merupakan uji untuk mengetahui apakah item- item dalam instrumen penelitian dapat mengukur variabel-variabel yang diteliti. Uji ini dilakukan dengan membandingkan indeks korelasi product pearson dengan level signifikansi 5\% dengan nilai kritisnya. Validitas juga bisa dilihat dari indeks korelasi product moment pearson $\left(r_{\text {hitung }}\right)$ dibandingkan dengan

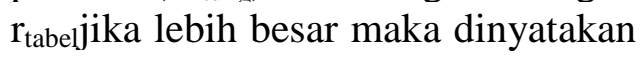
valid dan sebaliknya. 
Tabel 2. Hasil Uji Validitas

\begin{tabular}{ccccc}
\hline Variabel & Item & $\boldsymbol{r}_{\text {hitung }}$ & $\boldsymbol{r}_{\text {tabel }}$ & Keterangan \\
\hline Sense (panca Indera) X1 & X1.1 & 0,906 & 0,195 & Valid \\
& X1.2 & 0,888 & 0,195 & Valid \\
Feel (perasaan) X2 & X1.3 & 0,903 & 0,195 & Valid \\
& X2.1 & 0,848 & 0,195 & Valid \\
\multirow{3}{*}{ Think (berfikir) X3 } & X2.2 & 0,852 & 0,195 & Valid \\
& X2.3 & 0,892 & 0,195 & Valid \\
Act (tindakan) X4 & X3.1 & 0,892 & 0,195 & Valid \\
& X3.2 & 0,915 & 0,195 & Valid \\
& X3.3 & 0,915 & 0,195 & Valid \\
Relate (hubungan) X5 & X4.1 & 0,781 & 0,195 & Valid \\
& X4.2 & 0,740 & 0,195 & Valid \\
Kepuasan Pelanggan (Z) & X4.3 & 0,792 & 0,195 & Valid \\
& X5.1 & 0,738 & 0,195 & Valid \\
& X5.2 & 0,753 & 0,195 & Valid \\
Loyalitas Pelanggan (Y) & X5.3 & 0,800 & 0,195 & Valid \\
& Z1 & 0,833 & 0,195 & Valid \\
& Z2 & 0,790 & 0,195 & Valid \\
& Z3 & 0,888 & 0,195 & Valid \\
& Y2 & 0,859 & 0,195 & Valid \\
& Y3 & 0,906 & 0,195 & Valid \\
& & 0,890 & 0,195 & Valid \\
\hline
\end{tabular}

Berdasarkan tabel di atas dapat dijelaskan bahwa keseluruhan item pertanyaan variabel experiential marketing, kepuasan pelanggan, dan loyalitas pelanggan memiliki nilai $r$ hitung lebih besar daripada $\mathrm{r}$ tabel. Hal ini berarti seluruh item pertanyaan yang digunakan dalam penelitian ini dinyatakan layak atau valid.

Tabel 3. Uji Reliabilitas

\begin{tabular}{lccc}
\hline \multicolumn{1}{c}{ Variabel } & $\begin{array}{c}\text { Koefisien } \\
\text { Reliabilitas }\end{array}$ & $\begin{array}{c}\text { Nilai Kritis } \\
\text { Reliabilitas }\end{array}$ & Keterangan \\
\hline Sense (Panca Indera) (X1.1) & 0,881 & 0,6 & Reliabel \\
Feel (Perasaan) (X1.2) & 0,830 & 0,6 & Reliabel \\
Think (Berfikir) (X1.3) & 0,892 & 0,6 & Reliabel \\
Act (tindakan) X1.4 & 0,657 & 0,6 & Reliabel \\
Relat (hubungan) (X1.5) & 0,641 & 0,6 & Reliabel \\
Kepuasan Pelanggan (Z) & 0,786 & 0,6 & Reliabel \\
Loyalitas Pelanggan (Y) & 0,861 & 0,6 & Reliabel \\
\hline
\end{tabular}

Berdasarkan Tabel 3 diketahui bahwa tiap variabel yang diteliti mempunyai nilai koefisien alpha cronbach lebih besar 0,6 sehingga dapat dikatakan variabel yang digunakan dalam penelitian ini sudah reliabel atau dapat menghasilkan jawaban responden yang konsisten.

Tabel 4. Hasil Analisis Experiental Marketing terhadap Kepuasan Pelanggan

\begin{tabular}{ccccc}
\hline Pengaruh & Koefisien Regresi & Std. Error & T-hitung & P-Value \\
\hline $\mathrm{X} \rightarrow \mathrm{Z}$ & 0,320 & 0,029 & 5,994 & 0,000 \\
\hline
\end{tabular}


Hasil pengujian menunjukkan terdapat pengaruh positif dan signifikan antara Experiential Marketing terhadap Kepuasan Pelanggan, karena t-hitung $(5,994)$ lebih besar dari t-tabel $(0,195)$ dan $\mathrm{p}$ value $(0,000)$ lebih kecil dari alpha 5
$\%(0,050)$. Koefisien regresi sebesar 0,320 lebih besar dari 0,05 maka menunjukkan bahwa apabila Experiential Marketing semakin baik maka akan secara signifikan meningkatkan kepuasan pelanggan, begitu pula sebaliknya.

Tabel 5. Hasil Analisis Kepuasan Pelanggan Terhadap Loyalitas Pelanggan

\begin{tabular}{ccccc}
\hline Pengaruh & $\begin{array}{c}\text { Koefisien } \\
\text { Regresi }\end{array}$ & Std. Error & T-hitung & P-Value \\
\hline KP $\rightarrow$ LP & 0,428 & 0,091 & 5,520 & 0,000 \\
\hline
\end{tabular}

Hasil pengujian menunjukkan terdapat pengaruh positif dan signifikan antara Kepuasan Pelanggan terhadap Loyalitas Pelanggan karena t-hitung $(5,520)$ lebih besar dari t-tabel $(0,195)$ dan $\mathrm{p}$ value $(0,000)$ lebih kecil dari alpha 5
$\%(0,050)$. Koefisien regresi sebesar 0,428 lebih besar dari 0,05 maka menunjukkan bahwa apabila Kepuasan Pelanggan semakin meningkat maka akan secara signifikan meningkatkan loyalitas pelanggan, begitu pula sebaliknya

Tabel 6. Hasil Analisis Experiental Marketing Terhadap Loyalitas Pelanggan

\begin{tabular}{ccccc}
\hline Pengaruh & $\begin{array}{c}\text { Koefisien } \\
\text { Regresi }\end{array}$ & Std. Error & T-hitung & P-Value \\
\hline EM $\rightarrow$ LP & 0,278 & 0,037 & 2,904 & 0,001 \\
\hline
\end{tabular}

Hasil pengujian menunjukkan terdapat pengaruh positif dan signifikan antara Experiential Marketing terhadap Loyalitas Pelanggan karena t-hitung $(2,904)$ lebih besar dari t-tabel $(0,195)$ dan $\mathrm{p}$ value $(0,001)$ lebih kecil dari alpha 5
$\%(0,050)$. Koefisien regresi sebesar 0,278 lebih besar dari 0,05 maka menunjukkan bahwa apabila Experiential Marketing semakin baik maka akan secara signifikan meningkatkan loyalitas pelanggan, begitu pula sebaliknya.

Tabel 7. Hasil Analisis Experiental Marketing Terhadap Loyalitas Pelanggan

\begin{tabular}{ccccc}
\hline Pengaruh & $\begin{array}{c}\text { Koefisien } \\
\text { Regresi }\end{array}$ & Std. Error & T-hitung & P-Value \\
\hline $\mathrm{X} \rightarrow \mathrm{Z} \rightarrow \mathrm{Y}$ & 0,169 & 0,019 & 5,531 & 0,001 \\
\hline
\end{tabular}

Hasil pengujian menunjukkan terdapat pengaruh positif dan signifikan antara Experiential Marketing terhadap Loyalitas Pelanggan melalui Kepuasan Pelanggan. Hal ini dapat dilihat dari t-hitung $(5,531)$ lebih besar dari ttabel $(0,195)$ dan p-value $(0,001)$ lebih kecil dari alpha $5 \%(0,050)$. Koefisien regresi sebesar 0,169 lebih besar dari 0,05 maka menunjukkan bahwa apabila Experiential 
Marketing semakin baik maka akan secara signifikan meningkatkan loyalitas pelanggan seiring dengan meningkatnya kepuasan pelanggan, begitu pula sebaliknya Experiential
Marketing yang semakin buruk secara signifikan dapat menurunkan loyalitas pelanggan seiring dengan menurunnya kepuasan pelanggan terhadap jasa

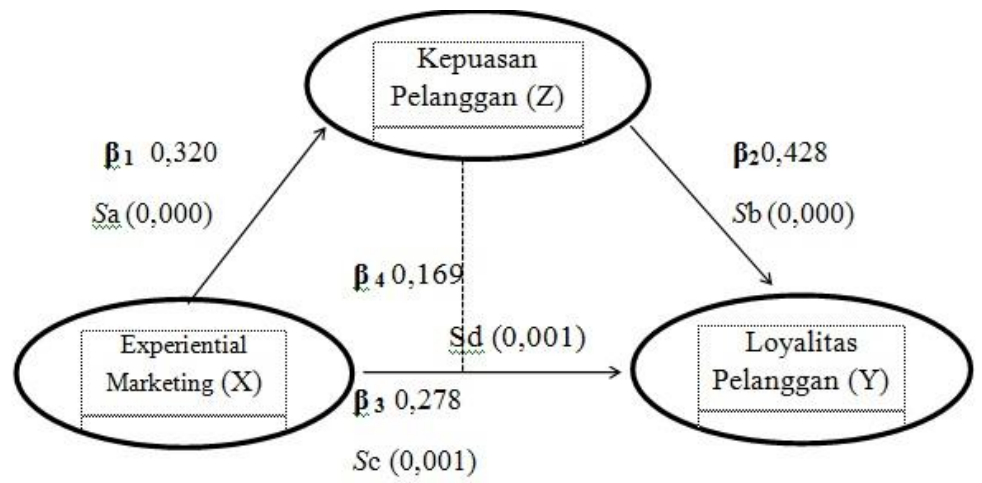

Gambar 3. Hasil Perhitungan Uji Sobel

Perhitungan sobel testnya adalah sebagai berikut, $\mathrm{z}$ value $=$ $\mathrm{a} * \mathrm{~b} / \mathrm{SQRT}(\mathrm{b} 2 * \mathrm{Sa} 2+\mathrm{a} 2 * \mathrm{Sb} 2)$

Jika menggunakan perhitungan interaktif melalui program calculation for the sobel test (Kristopher J. Preacher, 2017) maka dapat dilakukan dengan memasukkan nilai masing-masing koefisien regresi dan standart error yang akan diuji sehingga akan menghasilkan nilai $\mathrm{p}$ nya.

Nilai test statistic sebesar 4,86318285, standart error sebesar 0,02284306 maka nilai p-value yang dihasilkan adalah sebesar 0,00000116 . Oleh karena itu nilai pvalue lebih kecil 0,05 maka $\mathrm{H} 0$ diterima yang berarti ada efek mediasi pada variabel kepuasan pelanggan. Dengan demikian dapat dikatakan bahwa kepuasan pelanggan benar-benar mampu memediasi antara experiential marketing terhadap loyalitas pelanggan di Sengkaling Kuliner "SeKul" Malang.

\section{SIMPULAN}

Berdasarkan hasil analisis dan pembahasan maka dapat disimpulkan bahwa experiential marketingyang terdiri dari sense, feel, think, act, and relate di Sengkaling Kuliner termasuk dalam kategori baik. Kepuasan pelanggan termasuk dalam kategori puas, dan loyalitas pelanggan termasuk dalam kategori loyal. Experiential marketing berpengaruh signifikan terhadap kepuasan pelanggan, kepuasan pelanggan berpengaruh signifikan terhadap loyalitas pelanggan, experiential marketing berpengaruh signifikan terhadap loyalitas pelanggan, dan experiential marketing berpengaruh signifikan terhadap loyalitas pelanggan melalui kepuasan pelanggan.

\section{DAFTAR PUSTAKA}

Andriani, 2011, Analisis Pengaruh Experiential Marketing secara Terhadap Kepuasan dan Loyalitas Pelanggan: Kasus 
Hypermart Malang Town Square (MATOS, Jurnal Manajemen Pemasaran Modern Vol. 3 No. 1

Arikunto, Suharsimi. 2010. Prosedur Penelitian: Suatu Pendekatan Praktek. Jakarta: PT Rineka Cipta

Didi Suryadin, TR Sengkaling dan SEKUL/Sengkaling Kuliner . Artikel di akses pada tanggal 23 Oktober 2016. Darihttp://didisuryadin.student.u mm.ac.id/2016/08/31/trsengkaling-dan-sekulsengkaling-kuliner/

Griffin, Jill. 2005. CustomerLoyalty: Menumbuhkan\& mempertahankan Kesetiaan Pelanggan alih bahasa oleh Dr. Dwi Kartini Yahya. Jakarta: Erlangga

Ghozali, Imam. 2011. Aplikasi Analisis Multivariate Dengan Program SPSS. Semarang : UNDIP

Hasan, Ali. 2008. (Edisi Baru) Marketing. Yoyakarta : Media Pressindo

Hariwijaya M. dan Triton. 2011. Pedoman Penulisan Ilmiah Skripsi danTesis.Yogyakarta: ORYZA

Hermawan, Kartajaya, 2004. Marketing Venus. Jakarta : Gramedia Pustaka Utama.
Januar, T.Oeyono dan Dharmayanti, Diah. 2013, Analisa Pengaruh Experiential MarketingTerhadap Loyalitas Konsumen Melalui Kepuasan Sebagai Intervening Variabel di Tator Cafe Surabaya Town Square. Jurnal Manajemen Pemasaran Vol. 1, No. 2, 1-9

Kotler, Philip. 2009. Manajemen Pemasaran. Jilid I. Edisi ke 13. Jakarta: Erlangga

Sanusi, Anwar. 2014. Metodologi Penelitian Bisnis. Jilid I. Edisi ke 15. Jakarta : Salemba Empat.

Schmmit, Bernd. H, 1999. How to Get Customers to Sense, Feel, Think, Act, and Relate to Your Company and Brands. The free Press : New York

Sugiyono, 2007. Metode Penelitian Kuantitatif Kualitatif dan $R \& B$. Bandung. Alfabeta.

Tempo.co.id, Bukan Sekedar Makan. Artikel di akses pada tanggal 23 Oktober 2016. Dari https://m.tempo.co/read/news/20 09/04/14/108170283/bukansekedar-makan

Tjiptono, Fandy, 2001. Strategi Pemasaran; Edisi 3, Andi Offset, Yogyakarta.

Widayat, 2004. Metode Penelitian Pemasaran (Aplikasi Software SPSS). UMM Press, Malang 